\title{
DIAGNÓSTICO DA REALIDADE DOS CRIATÓRIOS DE AVES NA COMUNIDADE BASE FÍSICA - IPANGUAÇU/RN
}

\author{
José Geraldo Bezerra Galvão Júnior \\ Departamento de Gestão Fazenda-Escola - IFRN Campus Ipanguaçu \\ E-mail: josegeraldo@cefetrn.br \\ Epitácio Felizardo Bento \\ Departamento de Gestão Fazenda-Escola - IFRN Campus Ipanguaçu \\ E-mail: epitácio.bento@cefetrn.br \\ Adriano Fernandes de Souza \\ Aluno do Curso Técnico em Agroecologia - IFRN Campus Ipanguaçu \\ E-mail: adrianofernandes89@hotmail.com
}

\section{RESUMO}

Este trabalho objetivou realizar um diagnóstico de caracterização dos sistemas de criação de aves adotados na Comunidade Rural Base Física, município de Ipanguaçu/RN, com o intuito de produzir subsídios para orientação de ações de suporte técnico à comunidade local. Foram elaborados e aplicados 50 questionários, com questões relacionadas ao perfil socioeconômico dos criadores e aos aspectos zootécnicos relativos à criação de aves. Posteriormente, os dados foram agrupados e analisados graficamente, utilizando-se planilha eletrônica. Na análise dos resultados, a maioria dos entrevistados corresponderam ao gênero feminino (70\%), faixa etária de 41 a 60 anos (50\%), representados em sua maioria por agricultores (52\%), apresentando renda familiar de menos de 1 salário mínimo (16\%), até 2 salários (20\%) e acima de 2 salários mínimos (34\%). Na análise das respostas referentes aos aspectos zootécnicos da criação de aves, constatou-se um rebanho efetivo de 1046 aves, onde $81 \%$ dos entrevistados mantinham a criação para consumo da família. A avicultura representa grande importância na agricultura familiar da região, tanto na questão de segurança alimentar para a família quanto no aspecto econômico. A alimentação foi considerada o principal fator limitante para o desenvolvimento da criação, seguida da área para criação e presença de doenças nas aves. Programas de capacitação e assistência técnica devem ser implantados, para que possa haver um incremento quantitativo e qualitativo da criação de aves, principalmente, ligados aos aspectos de manejo alimentar e sanitário, bem como, no delineamento de modelos produtivos que expressem competitividade no setor.

PALAVRAS-CHAVE: avicultura, sistemas de criação, agricultura familiar. 


\section{DIAGNÓSTICO DA REALIDADE DOS CRIATÓRIOS DE AVES NA COMUNIDADE BASE FÍSICA - IPANGUAÇU/RN}

\section{INTRODUÇÃO}

Os sistemas de produção avícola classificam-se da seguinte maneira: Avicultura industrial, Avicultura Nativa e Avicultura Caipira ou Colonial. A avicultura industrial é a mais conhecida e é altamente tecnificada. A Avicultura Nativa é conhecida como sistema nativo brasileiro, onde as galinhas se reproduzem de forma natural via choco. As aves apresentam resistência às principais doenças e quase nunca são vacinadas nem vermifugadas, recebem apenas suplementação alimentar com grãos, ração, verduras, etc. e apresentam também baixa velocidade de crescimento. Os frangos da avicultura nativa produzem carcaças descarnadas e com pouca gordura. Enquadra-se nessa descrição o frango da roça, capoeira, nativo ou pé duro (FIGUEIREDO et al., 2001).

As criações domésticas de galinha caipira, praticadas nas unidades agrícolas familiares, se caracterizam pela sua forma de exploração extensiva, na qual inexistem instalações, bem como, a adoção de práticas de manejo que contemplem eficientemente os aspectos reprodutivos, nutricionais e sanitários. Tal fato resulta em índices de fertilidade e natalidade reduzidos (SAGRILO, 2003).

Savino (2007), relata que nesse sistema de criação, costuma-se substituir a ração por quirera ou milho em grão na tentativa de reduzir os custos de alimentação. Incorrendo, segundo o autor em perda nos índices de desempenho.

A criação alternativa de aves para o pequeno produtor não é aceita somente pela maior resistência das aves, pelos menores índices de mortalidade, e boa produtividade e sim como uma forma de agregar valores aos produtos produzidos pelas pequenas propriedades. No caso da integração da avicultura industrial, o investimento alto, a pequena margem de lucro e o risco considerável, garantem que o frango caipira ocupe um nicho do mercado deixado pelas empresas avícolas, proporcionando ao pequeno produtor ingressar na atividade avícola com investimentos iniciais bem menores, poucos riscos e considerável lucratividade.

Este trabalho objetivou realizar um diagnóstico de caracterização dos sistemas de criação de aves adotados na Comunidade Rural Base Física, município de Ipanguaçu/RN, com o intuito de produzir subsídios para orientação de ações de suporte técnico à comunidade local.

\section{METODOLOGIA}

O estudo foi desenvolvido pelo IFRN Campus Ipanguaçu por meio do projeto de extensão acadêmia "Criação de Aves em Sistemas Alternativos", junto a Comunidade Rural Base Física, município de Ipanguaçu/RN, localizada na região do Vale do Açu. O método utilizado para realização da pesquisa foi a aplicação de questionários, constando-se das seguintes fases: 1) elaboração e aplicação de questionários e 2) análise dos dados coletados. 
Os questionários foram elaborados com questões de múltipla escolha relacionadas ao perfil socioeconômico dos criadores e dos aspectos zootécnicos relativos à criação de aves, permitindo ao entrevistado responder a todas as questões atinentes a esse segmento do mercado.

Foram aplicados 50 questionários, nos meses de setembro e outubro do ano de 2009, procurando-se visitar as unidades familiares mais representativas durante a pesquisa, sendo todos válidos, com perguntas objetivas e abertas, as quais abordavam temas relacionados ao perfil do entrevistado, como gênero, domicílio, faixa etária, renda familiar, números de pessoas na família, ocupação; e aos aspectos zootécnicos da criação, como a espécie e número de aves criadas, forma de aquisição, doenças e manejo sanitário, manejo alimentar, instalações e equipamentos, destino da criação, principais dificuldades enfrentadas e forma de comercialização.

Os dados obtidos foram dispostos em planilha eletrônica para classificação, agrupados e analisados graficamente. Dentro de cada agrupamento, os percentuais foram calculados em relação ao número de alternativas disponíveis a cada questão formulada ou ao número de entrevistados que optaram pela alternativa em foco.

\section{RESULTADOS}

Os entrevistados corresponderam a $70 \%$ de pessoas do gênero feminino, faixa etária predominante entre 41 e 60 anos (50\%), e famílias que apresentaram renda familiar de menos de 1 salário mínimo (16\%), até 2 salários (20\%), e 34\% das famílias com renda acima de 2 salários mínimos (Figura 1).

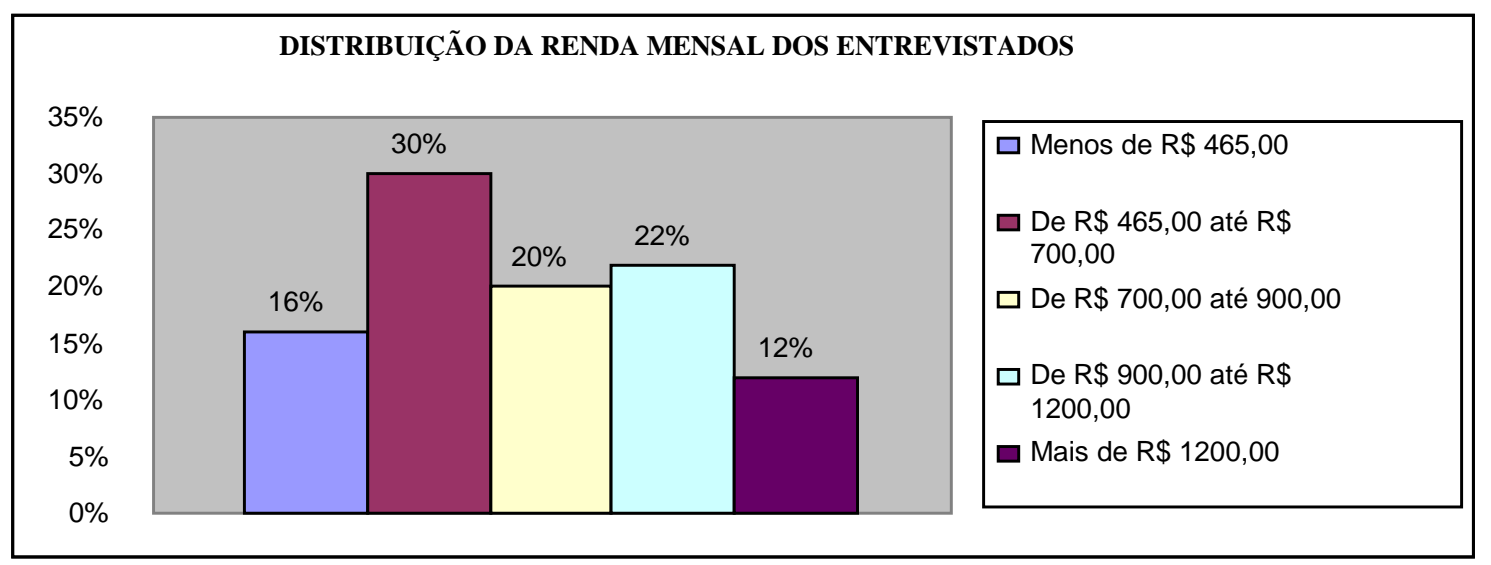

Figura 01. Distribuição da renda familiar mensal dos entrevistados

Na Figura 02 apresenta-se a distribuição dos entrevistados quanto ao seu grau de instrução, em que a maioria (52\%) é representada pelo ensino fundamental incompleto. Ainda analisando-se o perfil dos entrevistados, foi possível constatar que a sua maioria é representada por agricultores (52\%), podendo ser justificado pelo local de aplicação da pesquisa, como pode ser observado na Figura 03. 


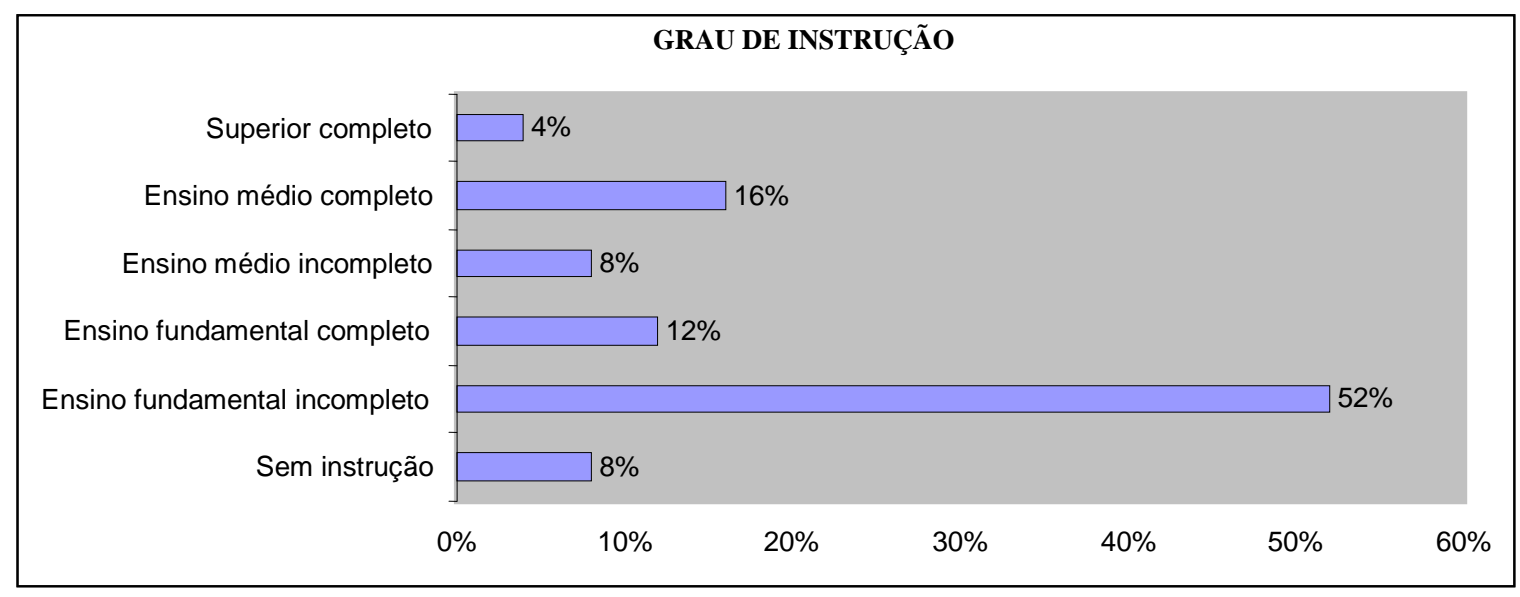

Figura 02. Grau de instrução dos entrevistados

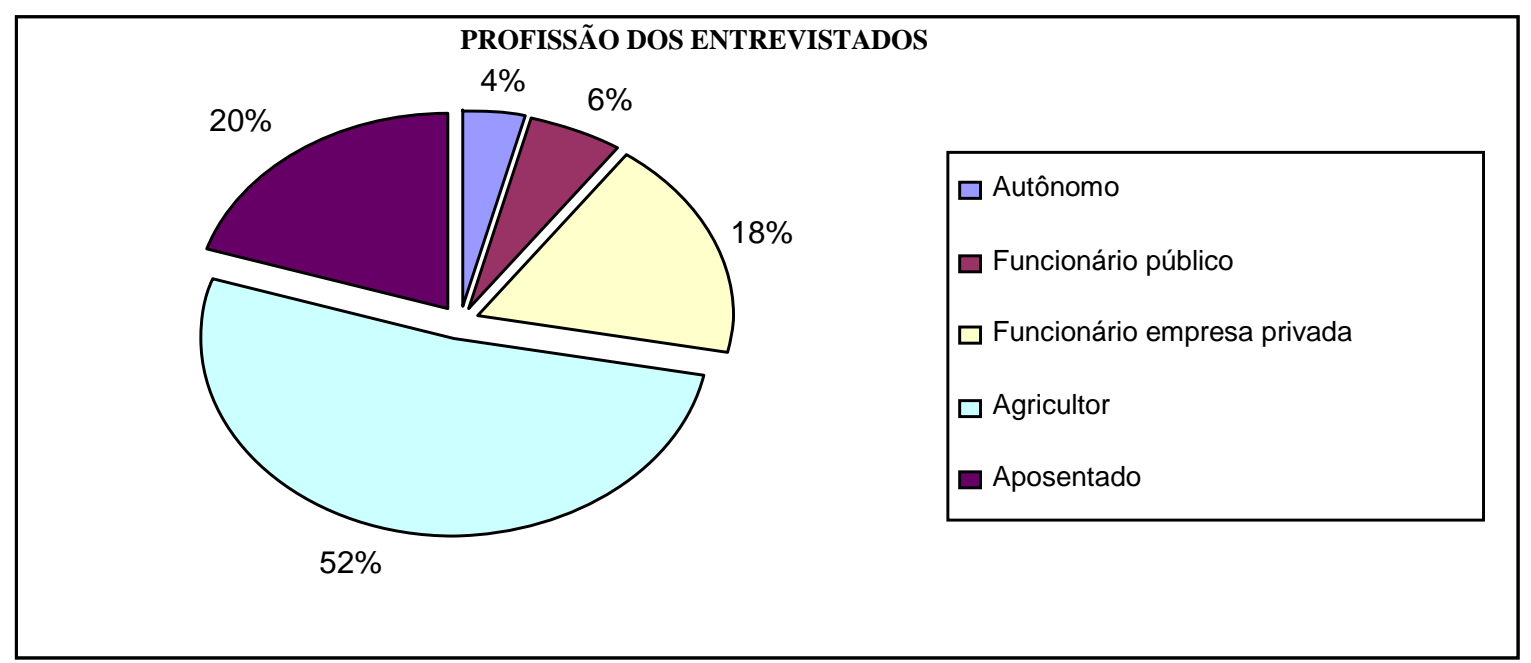

Figura 03. Distribuição dos entrevistados quanto à profissão.

Na análise das respostas referentes aos aspectos zootécnicos da criação de aves, constatouse um rebanho efetivo de 1046 aves, com predominância na criação de galinhas (Figura 04). Ao serem questionados sobre qual a finalidade da sua criação, $81 \%$ dos entrevistados responderam que mantinham a criação para o consumo da família, $11 \%$ para venda de carne e $8 \%$ para venda de ovos (Figura 05). Com relação à produção semanal de ovos, 52\% dos entrevistados responderam que varia entre 20 a 60 ovos produzidos por semana, $6 \%$ de 60 a 80 ovos/semana, não sendo diagnosticada produção superior a 80 ovos por semana, esses dados podem ser observados na Figura 06. 


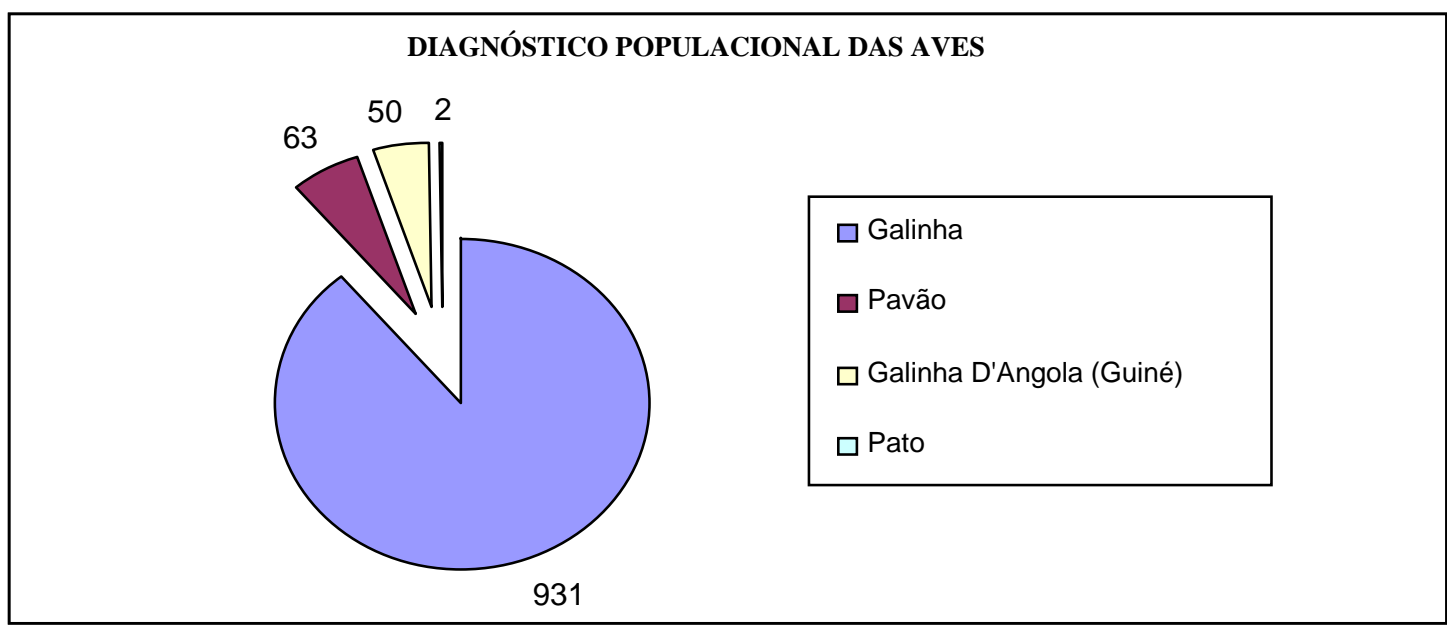

Figura 04. População total de aves na área de aplicação da pesquisa.

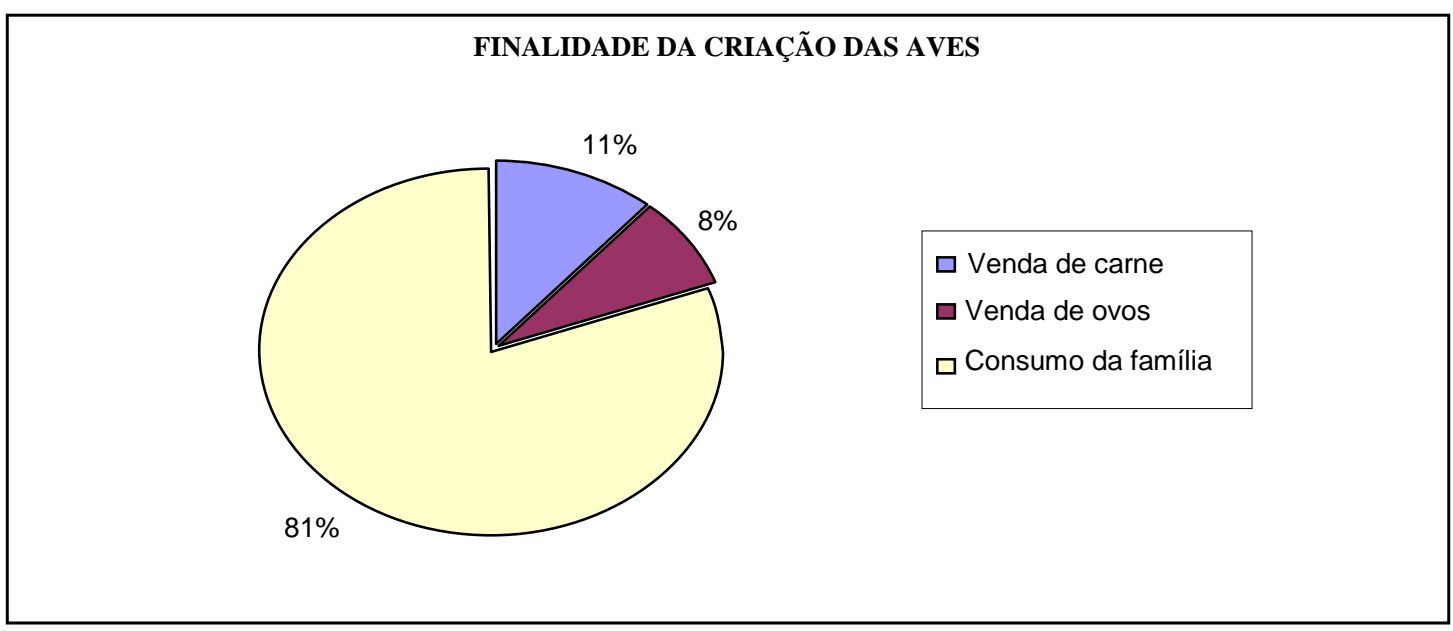

Figura 05. Análise da finalidade das criações de aves.

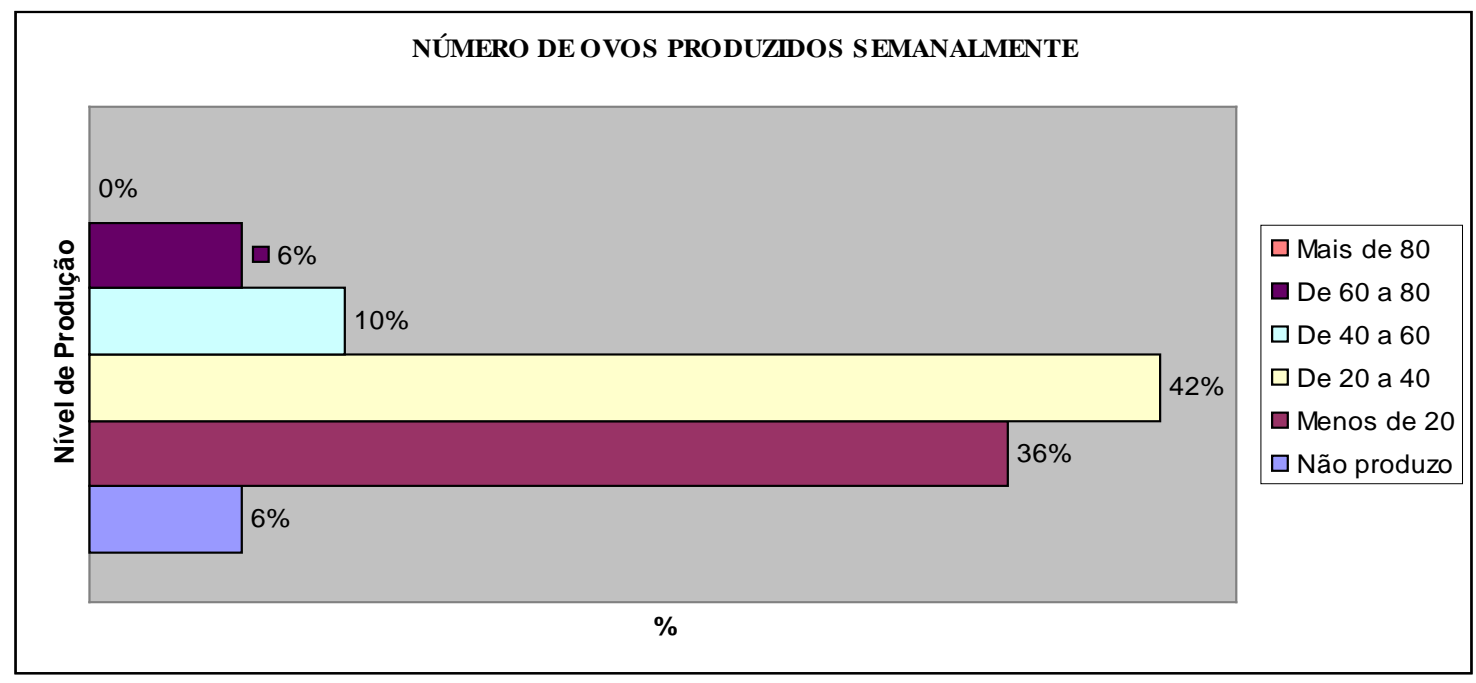

Figura 06. Diagnóstico da produção semanal de ovos. 
Um bom manejo alimentar, que atenda às exigências das aves é fundamental para que o criador alcance bons resultados no seu empreendimento. Assim, podem-se utilizar alimentos comerciais ou alimentos alternativos adquiridos (cultivados) na propriedade. $\mathrm{Na}$ maioria dos casos, pequenos criadores fornecem frutas, cereais e restos de comida. $\mathrm{Na}$ pesquisa em questão, 32\% dos entrevistados responderam fornecer alimentos comerciais, e $76 \%$ responderam que fornecem restos de comida às aves, sendo o milho a principal fonte energética utilizada. Além disso, 50\% dos entrevistados respoderam que o principal fator limitante da criação é alimentação (50\%), seguido da limitação de área para criação (22,\%) e doenças que acometem às aves (11\%).

Com relação aos problemas sanitários, por exemplo, tomando-se os cuidados necessários para prevenção de doenças, como profilaxia dos ambientes e uso de vacinas obrigatórias como Newcastle e a de Bouba Aviária, adotando um manejo adequado, provavelmente a ocorrência de doenças é pequena (HOLANDA, et al. 2003 e GODOI e ALBINO, 2007)

Finalmente, analisando-se os aspectos sanitários referentes à pesquisa, foi constatado que $96 \%$ dos criadores não aplicam vacinas nas aves. A doença mais diagnosticada é conhecida popularmente, como "gogo", que ataca o sistema respiratório das aves, tendo como principal fonte de combate o uso de limão na água. Além disso, foram citadas outras formas de controle alternativas de doenças, como: alho com leite, borra de café e mastruz com leite.

\section{CONCLUSÕES}

Com base nos resultados alcançados neste estudo, é possível ressaltar que a avicultura representa grande importância na agricultura familiar da região, tanto na questão de segurança alimentar para a família quanto no aspecto econômico. Apesar disso, a atividade é tratada como de fundo de quintal, praticada, em geral, extensivamente e, na maioria dos casos, de forma natural, sem a aplicação de técnicas fundamentais para a exploração e com resultados zootécnicos modestos.

Diante disso, torna-se necessário a elaboração e implantação de programas de capacitação e assistência técnica aos criadores, para que possa haver um incremento quantitativo e qualitativo da criação de aves, principalmente, ligados aos aspectos de manejo alimentar e sanitário, bem como, no delineamento de modelos produtivos que expressem competitividade no setor.

\section{REFERÊNCIAS BIBLIOGRÁFICAS}

FIGUEIREDO, E. A. P; PAIVA, D. P.; ROSA P. S.; ÁVILA, V. S.; TALAMINI, J. D. Diferentes denominações e classificação brasileira de produção alternativa de frangos. In: CONFERÊNCIA APINCO 2001 DE CIÊNCIA E TECNOLOGIA AVÍCOLA, Campinas, 2001. Anais...Campinas:FACTA, p.209 a 222, 2001.

GODOI, M. J. de S; ALBINO, L. F. Criação de galinhas caipiras. Viçosa: UFV, PEC, Núcleo de Difusão e Tecnologia, 2007. 42p. il. 
HOLANDA, J. S. de, et al. Manejo e produção de galinha caipira. Natal: Emparn, 2003. 72p. il.

SAGRILO, E. et al. Validação do Sistema Alternativo de Criação de Galinha Caipira. Embrapa, 2003. Disponível em: <www.sistemasdeproducao.cnptia.embrapa.br>. Acesso em: 17 de nov. de 2009.

SAVINO, V. J. M. et al. Avaliação de materiais genéticos visando à produção de frango caipira em diferentes sistemas de alimentação. Revista Brasileira de Zootecnia, Viçosa, v. 36, n. 3, June 2007 . Disponível em: <http://www.scielo.br>. Acesso em 17 de Nov. de 2009. 